\title{
The influence of wheelset flexibility on polygonal wear of locomotive wheels
}

\author{
Bo Peng ${ }^{1,2, *}$, Simon Iwnicki ${ }^{1}$, Philip Shackleton ${ }^{1}$, David Crosbee ${ }^{1}$, Yunshi Zhao ${ }^{1}$ \\ ${ }^{1}$ Institute of Railway Research, University of Huddersfield, Huddersfield, UK \\ ${ }^{2}$ CRRC Zhuzhou Locomotive Co.,Ltd. Zhuzhou, China \\ *E-mail: Bo.Peng@hud.ac.uk
}

\begin{abstract}
This paper reports on fundamental research to investigate the influence of wheelset flexibility on the development of wheel polygonization of a locomotive. After preparing a flexible wheelset model by importing a FE (Finite Element) model into the MBS (Multi-Body System) environment, the investigation work proceeded in 3 steps. Firstly, FRF (Frequency Response Function) of the contact responses against the track irregularity is analysed for a free wheelset and an on-track wheelset, with consideration of rotation effect. Secondly, the influence of the wheelset flexibility on the contact responses excited by white noise is investigated for straight and curved tracks. The final step is to check the influence of the wheelset flexibility on the development of wheel polygonization based on a developed prediction program for railway wheel polygonization. 6 scenarios are investigated with comparison between rigid and flexible wheelsets. Results show that, the wheelset flexibility cannot dominate the railway wheel polygonization in a general sense, unless some prerequisites are fulfilled to provide a suitable environment for the wheelset flexibility to be effectively and continually excited in order to fluctuate the contact responses, and thereby initiate wheel polygonization. The torsional mode of the wheelset can be effectively excited by stick-slip vibration due to saturated contact adhesion that can occur on track with small curve radii or by large traction torque. In this case, the developed wheel polygonization order will be exactly determined by the wheelset torsional modal frequency and the vehicle speed.
\end{abstract}

Keywords: Wheelset flexibility; polygonal wear; Archard wear model; rail/wheel contact responses; torsional mode; locomotive wheels.

\section{Introduction}

The phenomena of wheel polygonization has been found on all kinds of railway vehicles throughout the world for decades [1-7]. It introduces extra periodic excitation to the wheel-rail interface which can be very harmful to the vehicle-track system. The consequences can be noise, reduction of comfort, increased maintenance requirements and component damage. As speeds or axle loads increase the wheel polygonization has emerged as a critical issue for the safe and efficient operation of the rail network.

Researchers are continuing efforts to investigate the mechanism of railway wheel polygonization from varied perspectives. Some potential influencing factors have been revealed through simulation or field test, such as vehicle speed, wheelset flexibility [3, 8-11], track modes [12], wheelset imbalance [13], self-induced vibration [14], and so on. Among previous studies, a popular view is that the wheelset flexibility presents an important influence on the development of wheel polygonization. Specifically, the first bending mode of the wheelset has been argued to be the root cause for some orders of polygonization developed dominantly in particular vehicles (e.g. $18^{\text {th }}$ order for a locomotive [9], $9^{\text {th }}$ order for a metro train [1]). This hypothesis is supported by experiments finding that the natural frequency of the first bending mode of the wheelset is approximately corresponding to the passing frequency of the dominant orders of the wheel polygonization [1,9]. The lateral mode (the second bending mode) of the wheelset is also suspected to drive the development of the $24^{\text {th }}$ order of wheel polygonization in a Chinese locomotive, which however has not been verified [9]. In addition, the torsional mode was found theoretically and experimentally to be the reason for a $20^{\text {th }}$ order polygon of an electric locomotive in South Africa [15]. Two potential torsional vibration excitation mechanisms were explored, namely self-excited stick-slip vibration under saturated adhesion and forced excitation by the harmonics and inter-harmonics from a VFD (Variable Frequency Drive) driven AC (Alternating Current) traction motor [15].

Wheelset flexibility has also been argued as an important factor for the wheel/rail interface issues in the midfrequency range $(50 \mathrm{~Hz}-500 \mathrm{~Hz})[16,17]$, with wheel polygonization being a typical one. In terms of the influence of wheelset flexibility on the wheel/rail forces. Fermer and Nielsen found that the flexible wheels can considerably reduce the contact force [18]. Chaar and Berg found that the wheelset flexibility increases the lateral track forces significantly, which is in a good agreement with measurements [19]. However Guiral simulated reduced vibration of tangential and normal forces when taking into account the structural deformation of the wheelset by using a 
self-developed program that can deal with curve negotiation [20]. The difference could be due to different methods and cases. Baeza indicated that the rigid and non-rotating elastic wheelset model may misinterpret the wavelength fixation mechanism in corrugation calculation relative to rotating elastic wheelset [21]. Torstensson compared wheel-rail contact forces using rigid, non-rotating flexible, and rotating flexible wheelsets, and suggested to use the rotating flexible wheelset for load cases leading to large magnitude contact force components in the highfrequency range (above $1.5 \mathrm{kHz}$ ) [22].

The work presented here is carrying out a fundamental investigation through simulation with the specific aim of establishing whether wheelset flexibility can influence the development of railway wheel polygonization in a general sense. To this end, a comprehensive comparison is implemented between a flexible wheelset and a rigid wheelset in 3 aspects: the frequency response function, the contact responses, and the development of wheel polygonalization.

\section{Modelling of flexible wheelset}

A simple wheelset instead of a full vehicle is deliberately adopted here to minimise interfering factors, as the major influencing factor of interest in this paper is the wheelset flexibility. A simple co-running sleeper following the wheelset is used to simply represent the track flexibility. Guidance forces with linear stiffness and damping in 3 axes are applied at both sides of the wheelset axle, representing the dynamic coupling effect from the bogie frame. A wheelset of a Chinese locomotive with axle load (23 Tonne) is adopted as the research object. The wheel profile is JM3 [23], and the rail profile is CN60 [24]. The main parameters of the model are listed in Table 1.

Table 1 Main model parameters

\begin{tabular}{lll}
\hline Main parameters & Value & Unit \\
\hline Wheelset mass & 4560 & $\mathrm{~kg}$ \\
Radius & 0.625 & $\mathrm{~m}$ \\
Wheelset Ixx & 2822 & $\mathrm{~kg} \cdot \mathrm{m}^{2}$ \\
Wheelset Iyy & 737 & $\mathrm{~kg} \cdot \mathrm{m}^{2}$ \\
Wheelset Izz & 2822 & $\mathrm{~kg} \cdot \mathrm{m}^{2}$ \\
Longitudinal stiffness of primary suspension & $3.6 \mathrm{e} 7$ & $\mathrm{~N} / \mathrm{m}$ \\
Lateral stiffness of primary suspension & $4.8 \mathrm{e} 6$ & $\mathrm{~N} / \mathrm{m}$ \\
Vertical stiffness of primary suspension & $2.9 \mathrm{e} 6$ & $\mathrm{~N} / \mathrm{m}$ \\
Vertical damping of primary suspension & $4 \mathrm{e} 4$ & $\mathrm{Nm} / \mathrm{s}$ \\
Vertical stiffness of ballast & $1.5 \mathrm{e} 8$ & $\mathrm{~N} / \mathrm{m}$ \\
Vertical damping of ballast & $1.9 \mathrm{e} 5$ & $\mathrm{Ns} / \mathrm{m}$ \\
\hline
\end{tabular}

The geometry of the wheelset is simplified by equally distributing the mass of the attachments (gear, gear box and motor suspension tube) on the wheelset to avoid a large initial imbalance introduced by the attachments that can interfere with the observation of the influence of the wheelset flexibility. After successively using SolidWorks for geometry modelling, Hypermesh for meshing, and Abaqus for generating the FE substructure, the flexible wheelset was imported into Simpack through the 'Craig-Bampton' method [25], which is a method for reducing the size (degrees of freedom) of the FE model to integrate the flexible model (known as a superelement) into the MBS software. Figure 1 shows the meshing and the selection of the master nodes of the wheelset. Table 2 lists the flexible modes with comparison between the modal frequencies and substructure frequencies showing the reduced accuracy due to the selection of master nodes. It is worthy to mention that the wheelset flexible frequencies in simulation are not accurate compared to those in reality due to the simplification of the geometry. However, the intention is not to faithfully replicate the modal response of a specific wheelset, but to have plausible characteristics to work with. The specific value of the flexible frequencies are not expected to affect this fundamental research which is focusing on whether some flexible modes can be effectively excited to initiate the wheel polygonization. 


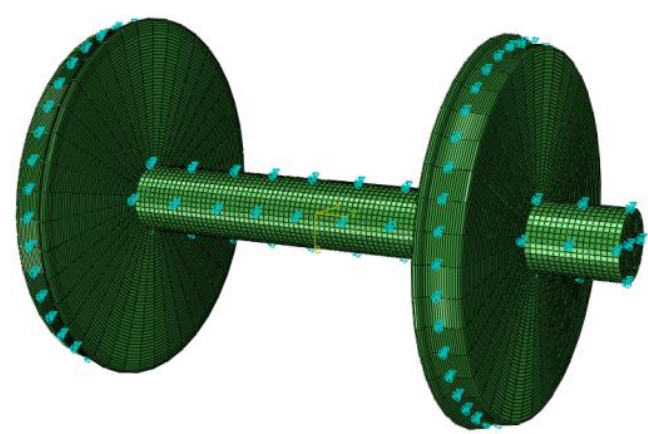

Figure 1 Meshing and selection of master nodes of the wheelset

Table 2 Wheelset flexible modes

\begin{tabular}{lllll}
\hline Modes & $\begin{array}{l}\text { Modal } \\
\text { frequency [Hz] }\end{array}$ & $\begin{array}{l}\text { Substructure } \\
\text { frequency }[\mathrm{Hz}]\end{array}$ & $\begin{array}{l}\text { Discrepancy } \\
{[\%]}\end{array}$ & Remarks \\
\hline 1 & 50.03 & 50.05 & $0.04 \%$ & Torsional mode \\
2 & 71.18 & 71.30 & $0.17 \%$ & $1^{\text {st }}$ bending mode \\
3 & 135.33 & 136.00 & $0.50 \%$ & $2^{\text {nd }}$ bending mode \\
4 & 278.65 & 288.07 & $3.38 \%$ & Umbrella mode \\
\hline
\end{tabular}

Knowing that the operational speed of the locomotive being investigated in this paper is relative slow (normally below $80 \mathrm{~km} / \mathrm{h}$ ), the first 6 modes with frequencies below $300 \mathrm{~Hz}$ are chosen for the investigation in this paper. The modal shapes of the $1^{\text {st }}$ bending mode, the $2^{\text {nd }}$ bending mode and the umbrella mode are illustrated in Figure 2. As a symmetrical rotating body, the bending modes have two orthogonal identical shapes that will occur simultaneously in the global Cartesian coordinate system, which can lead to frequency bifurcation for high-speed rotation. In addition, a very small wheelset imbalance is unavoidably introduced to Simpack along with the transfer of the flexible wheelset body due to the FE meshing. This imbalance cannot be eliminated, but can only be minimised by refining the FE mesh. In order to get comparable results, the rigid wheelset, used for comparison, is configured with the same initial imbalance.

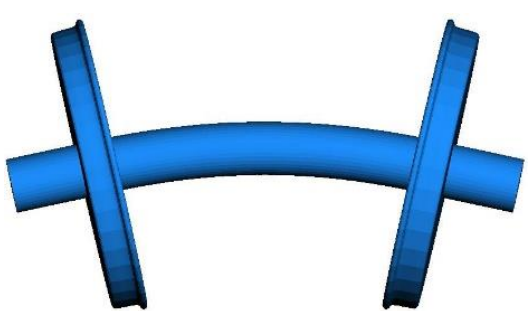

(a) the $1^{\text {st }}$ bending mode $(71 \mathrm{~Hz})$

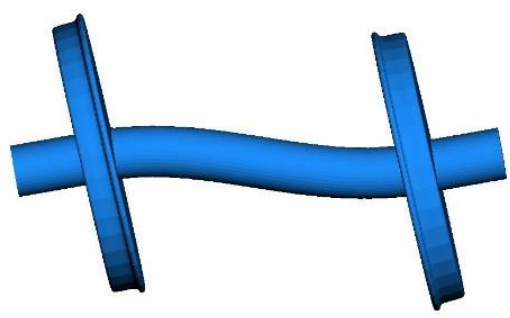

(b) the $2^{\text {nd }}$ bending mode $(136 \mathrm{~Hz})$

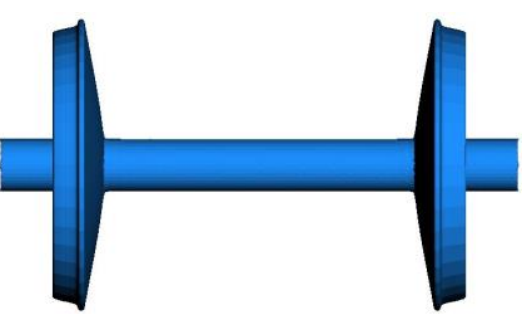

(c) umbrella mode $(288 \mathrm{~Hz})$

Figure 2 Flexible mode shapes of the wheelset

\section{Frequency response analysis}

The FRF analysis of the flexible wheelset is important as it can show whether the flexible modes can be easily excited within a given frequency range. To obtain an informative FRF of the wheelset for the issue of polygonal wear occurring at the wheel/rail interface, two special aspects need to be pointed out in terms of the input/output configuration. Firstly, the input of the wheelset FRF should be the track irregularity which is a displacement input, because it is the only external excitation in reality if the motor vibration is not accounted for. The normal force at the contact point should not be taken as the input, but one of the outputs. Secondly, the output point is also at the wheel/rail contact position for the interest is focused on the contact responses that determines the wheel/rail wear. However, the contact patch is a moving patch around the wheel circumference. As a result, the rotating effect of the wheelset should be taken into consideration. To carry out such kind of FRF analysis of the wheelset, two circumstances are investigated, namely the free wheelset and the on-track wheelset. 


\subsection{Free wheelset}

The configuration for the free wheelset FRF analysis is shown in Figure 3. A dummy ground is configured with a moved vertical joint driven by a vertical displacement excitation $\mathrm{dz}$ as the input. The contact between the wheelset and the dummy ground is established by adding a pair of special moved contact markers to the respective bodies. The two corresponding contact markers can locate the potential contact point 'online' during the simulation. The flexible deformation of the wheelset is automatically taken into account for the contact search, which allows a realistic simulation even the wheelset is rotating. A linear vertical spring is applied between the corresponding contact markers to approximately represent the normal force at the wheel/rail interface.

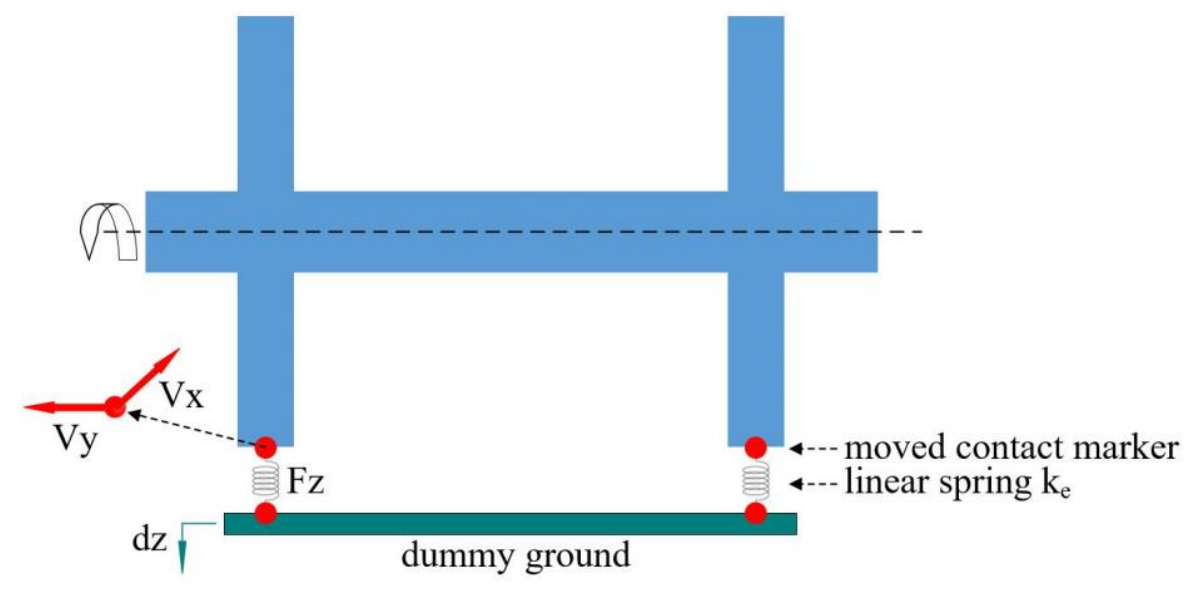

Figure 3 Configuration of FRF analysis for a free wheelset

The linear spring stiffness is estimated according to the non-linear Hertz normal force Equation (1) referring to [26].

$$
p(t)=\left[\frac{1}{G} \delta Z(t)\right]^{3 / 2}
$$

Where: $p(t)$ is the normal force $(\mathrm{N}), \delta Z(t)$ is the elastic penetration $(\mathrm{m})$. So that the non-linear Hertz contact stiffness $K$ can be written as:

$$
K=\frac{1}{G} p^{1 / 3}(t)
$$

Where: $G=3.86 R^{-0.115} \times 10^{-8}\left(m / N^{2 / 3}\right)$ for a worn profile tread [26], $R$ is the wheel radius (m).

Admittedly, the contact stiffness is varied with the normal force. However, to carry out a FRF analysis which can only be done for a linear system, the approximation has to be made. Given the preload normal force $\mathrm{P}_{\mathrm{n}}(112.364$ $\mathrm{kN}$ ), an equivalent linear normal stiffness $\mathrm{K}_{\mathrm{e}}$ is estimated as below.

$$
K_{e}=\frac{1}{G} p_{n}=112364 /\left(3.86 \times 0.625^{-0.115} \times 10^{-8}\right) \approx 1.2 \mathrm{e} 9 \quad(N / m)
$$

The wheelset can rotate with an initial angular velocity without stopping as no friction is applied against the rotation. The normal force $\mathrm{Fz}$, the lateral velocity $\mathrm{Vy}$ and the longitudinal velocity $\mathrm{Vx}$ of the contact marker on the wheels are set as the outputs to investigate the contact responses in 3 directions. The velocity rather than the displacement of the contact point is adopted as the output because the creepage is of more interest as an important factor in determining the wheel wear, although the FRF shape of the displacement and velocity are similar (but still different). The FRF is analysed with comparison between the rigid wheelset, non-rotating flexible wheelset, rotating flexible wheelset $(120 \mathrm{~km} / \mathrm{h})$, and rotating flexible wheelset $(350 \mathrm{~km} / \mathrm{h})$, so that the influence of the wheelset flexibility as well as the rotating effect can be identified. The FRF analysis results are shown in Figure 4.

For the FRF of the normal force (see Figure 4 (a)), the wheelset flexibility does not show obvious effect, with only a slight difference observed at the position of the $1^{\text {st }}$ bending modal frequency (see the red circle in Figure 4 (a)). However, the FRF of the lateral velocity of the contact point can be significantly affected by the wheelset flexibility (see Figure 4 (b)). Firstly, for the rigid wheelset, a vertical displacement excitation at the contact position can hardly lead to a lateral displacement of the contact point. So the FRF of the rigid wheelset is at a very low level and consequently not comparable with that of the flexible wheelsets. Secondly, for the flexible wheelsets, two distinct peaks appear at the position of the $1^{\text {st }}$ bending mode $(71 \mathrm{~Hz})$ and the umbrella mode $(288 \mathrm{~Hz})$. This is 
because these two modal shapes allow a lateral deformation at the contact point. Thirdly, the rotation effect is observed at the position of the $1^{\text {st }}$ bending mode (see the red circle in Figure 4 (b)). In terms of the FRF of the longitudinal velocity (see Figure 4 (c)), the $1^{\text {st }}$ bending modal frequency is also found appearing in the FRF for the flexible wheelsets. The rotation will further amplify the FRF amplitude, and the peak at the $1^{\text {st }}$ bending frequency becomes more predominant. In addition, there is a dominant peak at around $116 \mathrm{~Hz}$ in all the FRFs which is socalled $\mathrm{P} 1$ resonance. The frequency of $\mathrm{P} 1$ force is determined by the un-sprung mass (wheel and associated axle mass, bearings and brake gear) and the Hertzian stiffness at the contact patch [27]. But this P1 frequency will be shifted to a high frequency (around $672 \mathrm{~Hz}$ ) when the track flexibility is considered, which can be seen in the following section. Actually this P1 frequency will be even higher in reality than in simulation, and it will be filtered as the interested frequency range is below $300 \mathrm{~Hz}$.

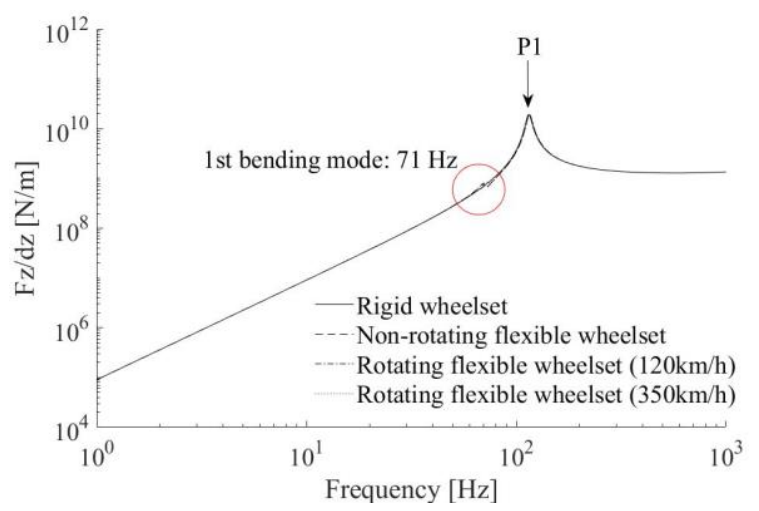

(a) Fz/dz

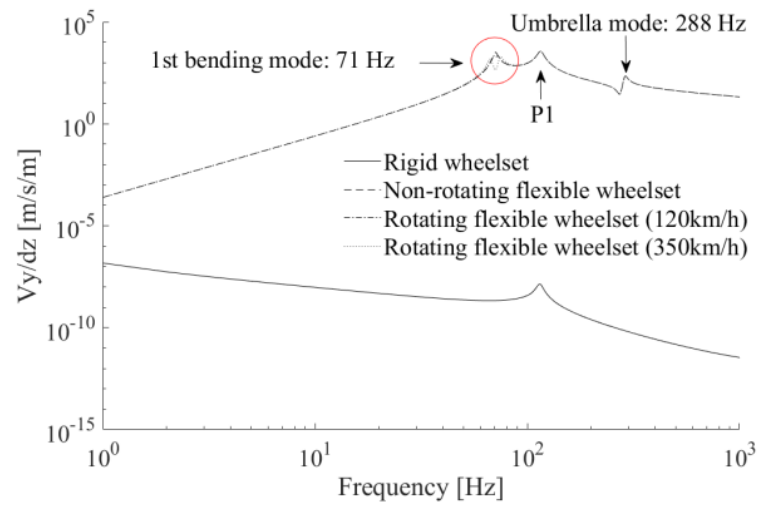

(b) $\mathrm{Vy} / \mathrm{dz}$

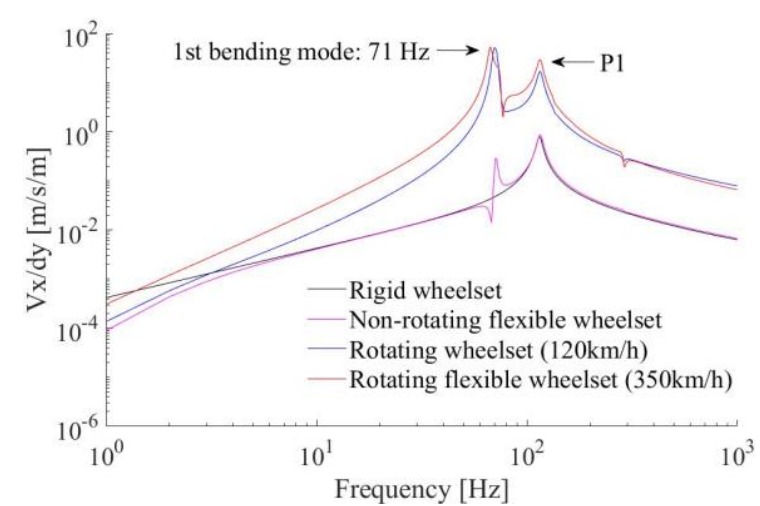

(c) $\mathrm{Vx} / \mathrm{dz}$

Figure 4 FRFs of the contact responses for a free wheelset with comparison between rigid wheelset, non-rotating flexible wheelset, rotating flexible wheelset $(120 \mathrm{~km} / \mathrm{h})$, and rotating flexible wheelset $(350 \mathrm{~km} / \mathrm{h})$ : (a) the normal force Fz over the vertical displacement dz, (b) the lateral velocity Vy over the vertical displacement dz, and (c) the longitudinal velocity $\mathrm{Vx}$ over the vertical displacement $\mathrm{dz}$

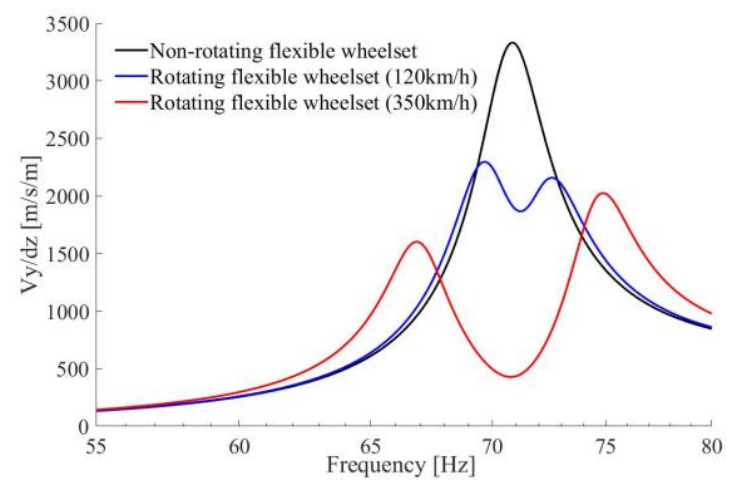

Figure 5 The rotation effect for the $1^{\text {st }}$ bending mode of wheelset

Figure 5 shows the detail of the rotation effect for the $1^{\text {st }}$ bending mode. For a rotating flexible component, there will be a divergence effect for the flexible modes that have two orthogonal shapes (e.g. the $1^{\text {st }}$ bending mode of 
the wheelset). Due to the rotation, eigenmodes of multiplicity two will split into backward and forward whirl modes which diverge in frequency with increasing rotational speed [22]. As can be seen in Figure 5, the divergence phenomena is not obvious for a rotating speed of $120 \mathrm{~km} / \mathrm{h}$ which is the maximal operating speed of the locomotive wheelset investigated in this paper. However, if the rotating speed is increased to $350 \mathrm{~km} / \mathrm{h}$, the divergence phenomena becomes apparent. This implies that the necessity of considering the rotation effect mainly depends on the train speed. For a low-speed locomotive, the rotation effect is negligible.

\subsection{On-track wheelset}

An alternative way to investigate the frequency response of the contact is to run the wheelset on an actual track. This is allowed in Simpack by assigning local excitations to the rails, by which the contact responses against the track irregularity in frequency domain can be obtained directly. The local excitation is a type of distance frequency domain excitation, and will be automatically converted into time frequency domain with the vehicle speed. This method facilitates the investigation of the FRF of the contact responses in a more realistic situation where the nonlinear wheel/rail contact, the primary suspension, and the co-running sleeper can be accounted for. Note that the non-linear wheel/rail contact will be automatically linearized in this method. The comparison is implemented between rigid and flexible wheelsets running at $70 \mathrm{~km} / \mathrm{h}$. Higher speed is not considered in this case as the rotation effect is not obvious below $120 \mathrm{~km} / \mathrm{h}$. With the vertical track irregularity as the input, the contact FRF analysis results are shown in Figure 6.

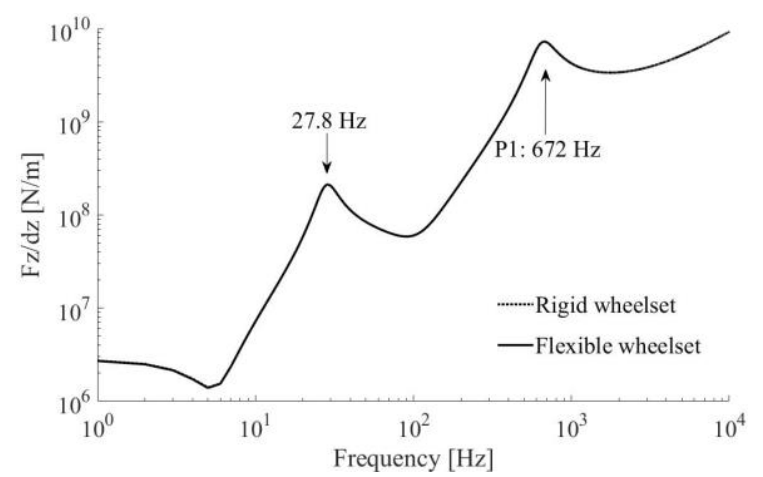

(a) $\mathrm{Fz} / \mathrm{dz}$

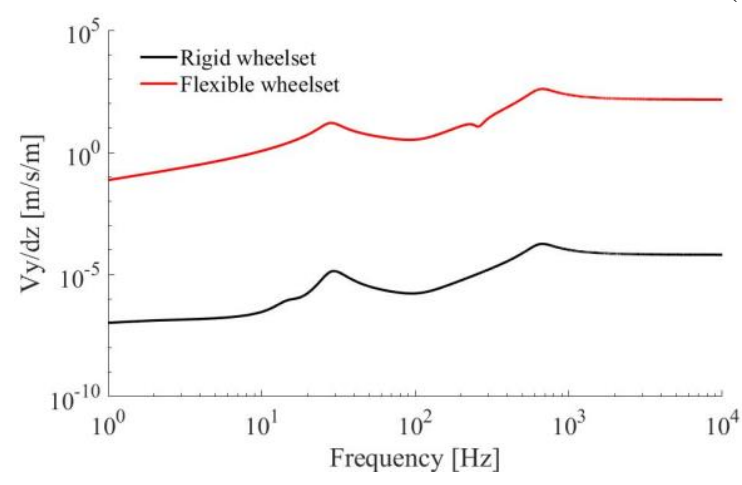

(b) $\mathrm{Vy} / \mathrm{dz}$

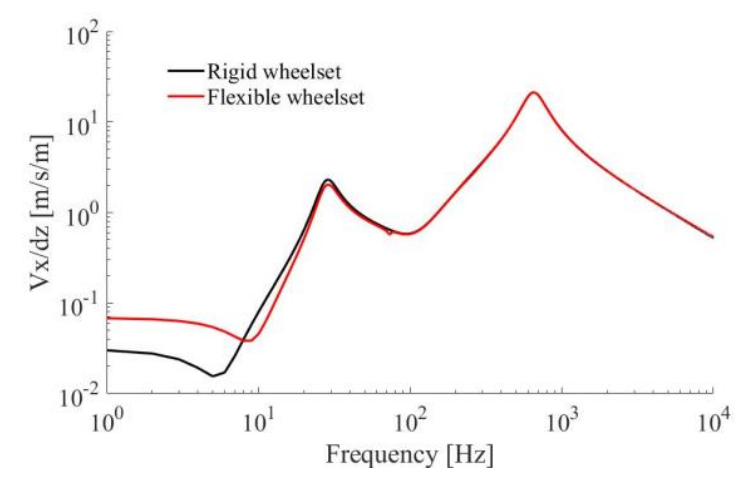

(c) $\mathrm{Vx} / \mathrm{dz}$

Figure 6 FRFs of the contact responses for an on-track wheelset with comparison between rigid and flexible wheelsets: (a) Normal force Fz over vertical track irregularity dz, (b) Lateral relative velocity Vy over vertical track irregularity dz, and (c) Longitudinal relative velocity Vx over vertical track irregularity dz

First of all, there are two dominant peaks in all the FRFs. The peak at $27.8 \mathrm{~Hz}$ is a rigid modal frequency of the wheelset $\&$ sleeper with respect to the ground, which is determined by the mass of wheelset \& sleeper and the vertical stiffness of the sleeper. The peak at $672 \mathrm{~Hz}$ is the P1 resonance which is increased compared to the free wheelset due to the track flexibility considered here. Despite this, the important aspect is that the wheelset flexibility does not demonstrate an obvious influence on the frequency components of the FRFs, except that the FRF amplitude of the lateral relative velocity is shifted to a higher level. In other words, no peaks corresponding to the wheelset flexible frequencies are found in the FRFs in any of the 3 directions. This implies that the wheelset flexible modes cannot easily be excited in an MBS simulation, which is confirmed in the following sections. This is not consistent with the free wheelset where the FRFs of the lateral and longitudinal velocity are found to be significantly influenced by the wheelset flexibility (See Figure 4 (b) and (c)). The reasons for this are not clear, 
but a suspicion is put on the normal contact model. It is found that if the normal contact stiffness is significantly increased (e.g. 100 times the normal value), the wheelset flexible modes can be successfully excited in the case of an on-track wheelset where the Hertz normal contact model is used. Although this is only a hypothetical test which is not realistic, it might draw attention to the normal contact model which is associated with the material and the elastic contact modelling, and imply that accurate contact stiffness values are critical to the realistic simulation of flexible wheelsets.

\section{Influence of wheelset flexibility on contact responses}

The Archard \& FASTSIM wear model, which is also known as the KTH (Royal Institute of Technology) wear model [28], is employed to calculate the circumferential wear depth with nine contact parameters as the inputs: normal force; creepages (longitudinal, lateral, and spin); contact patch size (semi-axis a and b); and Kalker coefficient $(\mathrm{C} 11, \mathrm{C} 22$, and C23). Note that the contact patch size and Kalker coefficients are dependent on the normal force. As a result, only the normal force and the creepages (Spin is not shown below) are in the scope of investigation. The instantaneous Archard wear depth is also included in the comparison. White noise with a flatPSD (Power Spectrum Density with a constant value) is used as the excitation of track irregularity. The upper frequency is $300 \mathrm{~Hz}$ and the amplitude is around $0.01 \mathrm{~mm}$. A large number of simulations under different circumstances (e.g. straight and curved tracks, vertical and lateral excitation, and traction) have been carried out to check whether, and in what conditions, the flexible wheelset modes can be effectively excited to influence the contact parameters in both time and frequency domain. But only representative results of two scenarios are presented: straight track and curved track with small radius.

\subsection{Straight track}

At a speed of $70 \mathrm{~km} / \mathrm{h}$, with vertical track irregularity of white noise as the excitation, the wheelset is run on a straight track for 50 revolutions. The contact responses of the normal force, longitudinal creepage, lateral creepage and the Archard wear depth for both rigid and flexible wheelsets are shown in Figure 7.

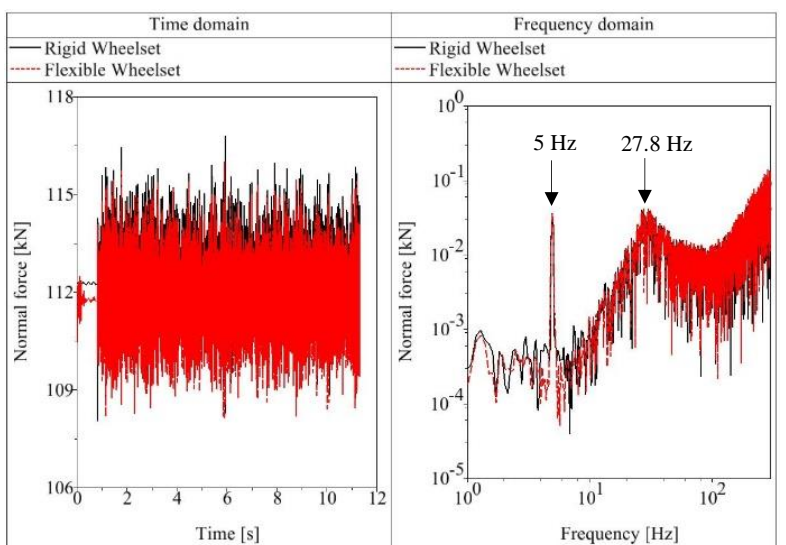

(a) Normal force

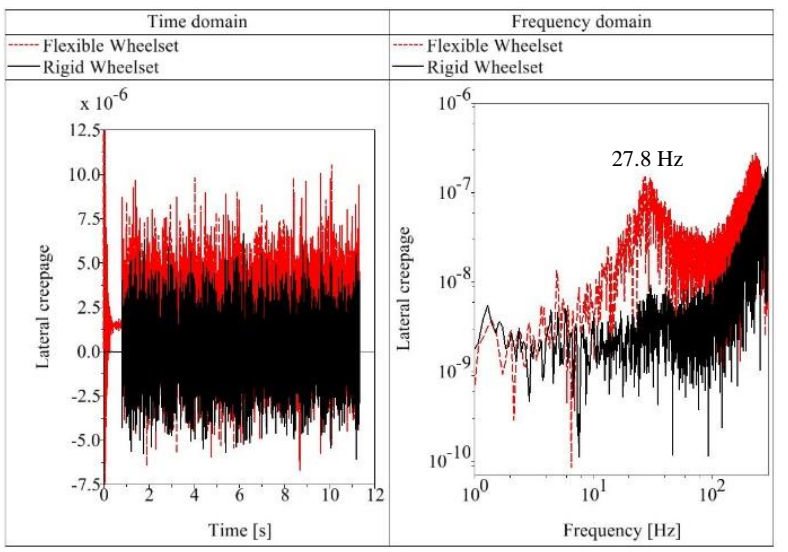

(c) Lateral creepage

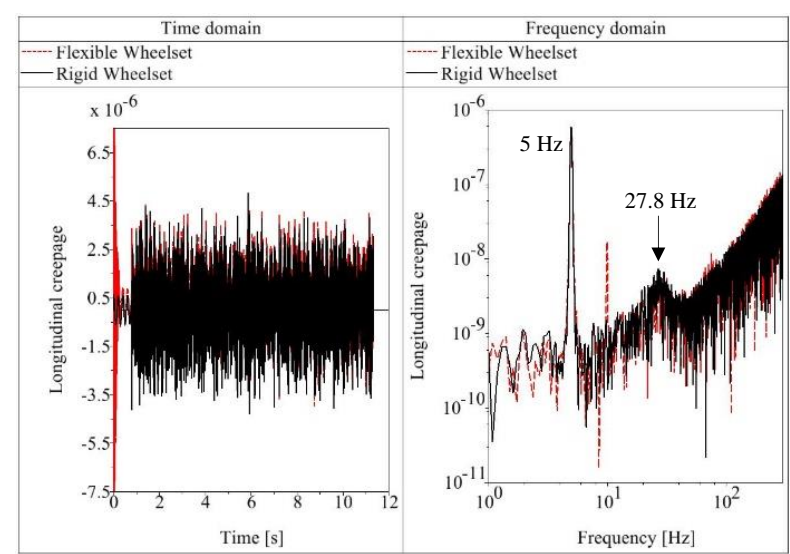

(b) Longitudinal creepage

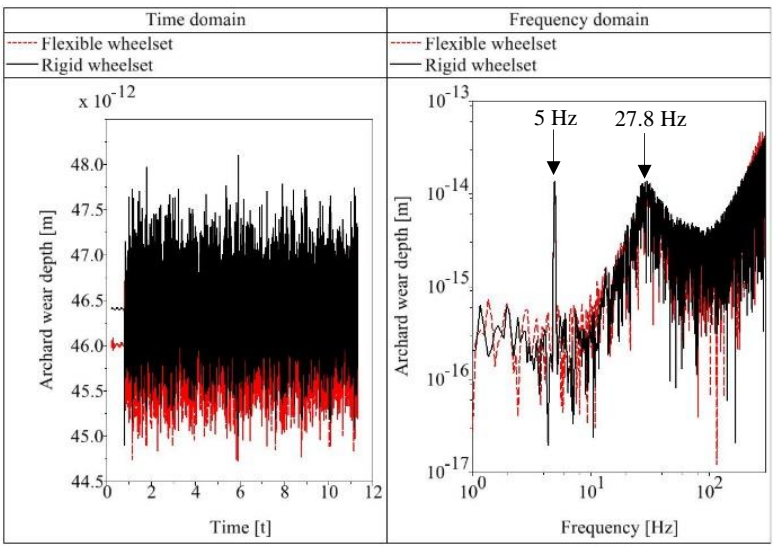

(d) Archard wear depth 
Figure 7 Contact responses excited by vertical track irregularity (white noise) on a straight track with comparison between rigid and flexible wheelsets: (a) Normal force, (b) Longitudinal creepage, (c) Lateral creepage, and (d) Archard wear depth

Comparing the flexible wheelset with the rigid wheelset in the time domain, the normal force is slightly attenuated; the longitudinal creepage remains the same; however the lateral creepage is significantly increased. When comparing in the frequency domain, the normal force as well as the longitudinal creepage present negligible difference between rigid and flexible wheelsets, but the lateral creepage is largely increased due to the wheelset flexibility, as can be seen clearly in Figure 7 (c). When checking the wheel wear, it is found that the Archard wear depth is slightly decreased due to the wheelset flexibility in the time domain, while remains similar in the frequency domain between rigid and flexible wheelsets. Note that in the case of a straight track, the lateral creepage is at a low level. So even a largely increased lateral creepage has less weight than a slightly reduced normal force in determining the Archard wear depth. In addition, there are 2 obvious peaks in the frequency spectrum of contact responses and wheel wear. The peak at $5 \mathrm{~Hz}$ is due to the initial wheelset imbalance introduced by the FE meshing (see Section 2), which is also the rolling frequency (in this case: $70 / 3.6 / 3.925 \approx 5 \mathrm{~Hz}$ ). The peak at $27.8 \mathrm{~Hz}$ is due to the vertical rigid body mode of the wheelset \& sleeper with respect to the ground, which is determined by the mass of wheelset \& sleeper and the vertical stiffness of the sleeper. Other than these, there are no resonant peaks found for the wheelset flexible modal frequencies in the frequency spectrum for all 3 directions, which however is consistent with the FRFs of the on-track wheelset.

\subsection{Curved track with small radius}

A case of curved track with a very small radius of $100 \mathrm{~m}$ is presented here. At a speed of $50 \mathrm{~km} / \mathrm{h}$, with vertical track irregularity of white noise as the excitation, the wheelset is run on a curve of radius $100 \mathrm{~m}$ for 50 revolutions. The respective results are shown in Figure 8.

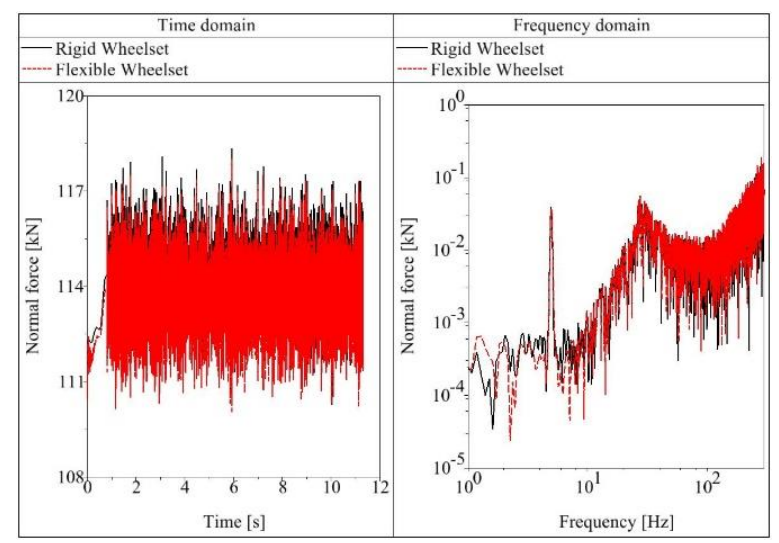

(a) Normal force

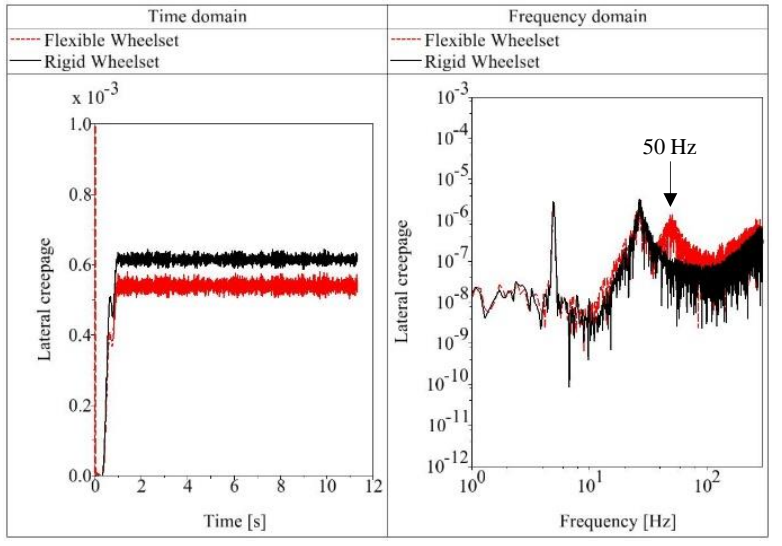

(c) Lateral creepage

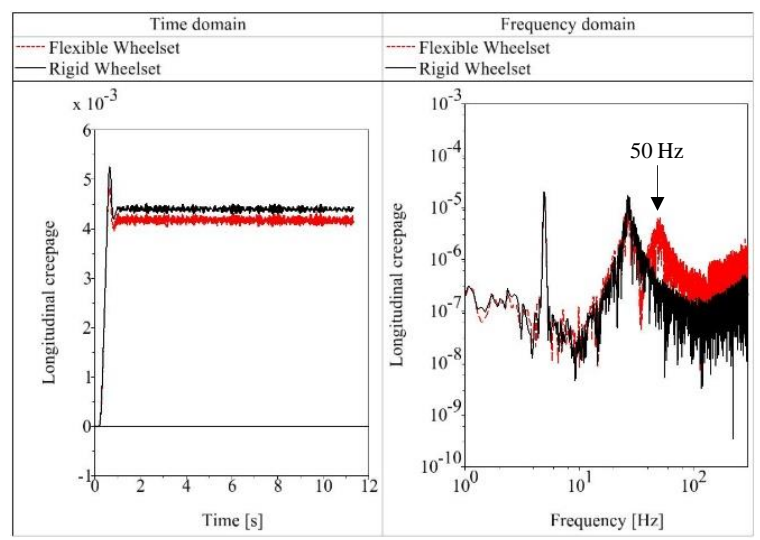

(b) Longitudinal creepage

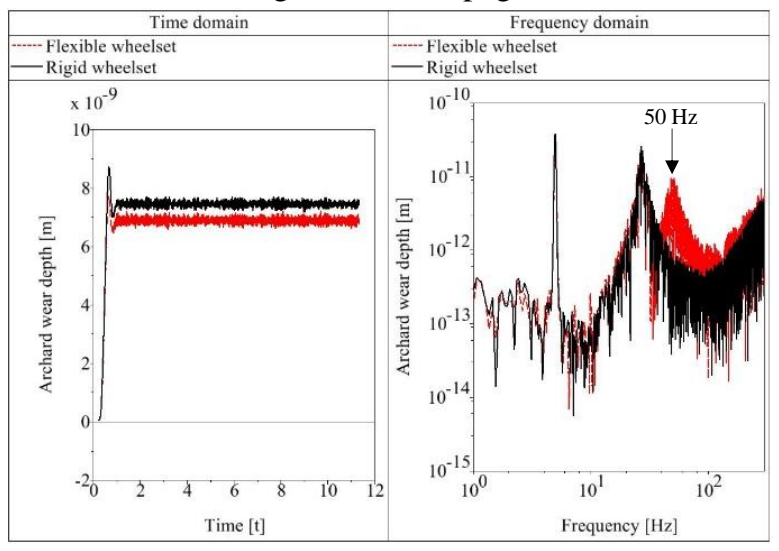

(d) Wear depth

Figure 8 Response of contact parameters excited by vertical track irregularity (white noise) on a curve (radius 100 m): (a) Normal force, (b) Longitudinal creepage, (c) Lateral creepage, (d) Archard wear depth

As can be seen from Figure 8, the peak normal force of the flexible wheelset is slightly less than that of the rigid wheelset. However, the frequency spectrums for both longitudinal creepage and lateral creepage present obvious 
discrepancy between rigid and flexible wheelsets. From around 40 to $300 \mathrm{~Hz}$, the frequency spectrum amplitude of the flexible wheelset is bigger than that of the rigid wheelset. Most importantly, there appears a distinct peak at around $50 \mathrm{~Hz}$ in the frequency spectrum of both longitudinal creepage and lateral creepage. It can be seen from Table 2 that, $50 \mathrm{~Hz}$ corresponds to the torsional modal frequency of the flexible wheelset, and the first 6 modal frequencies are just within the range from 40 to $300 \mathrm{~Hz}$. Consequently, it is believed that the torsional mode of the flexible wheelset is effectively excited to fluctuate the contact parameters in this case, which contributes to the resonant peak at $50 \mathrm{~Hz}$. And the first 6 modes of the flexible wheelset are also excited contributing, more or less, to the discrepancy in the frequency spectrum from around 40 to $300 \mathrm{~Hz}$. As expected, there appears an obvious resonant peak in the frequency spectrum of the Archard wear depth at the wheelset torsional modal frequency. Given this result, a natural question arises: why can the torsional mode be effectively excited to dominate the contact responses in the case of a small radius curve, while cannot for a straight track? To answer this question, a further investigation is carried out on the adhesion state of the contact, which is shown in Figure 9.

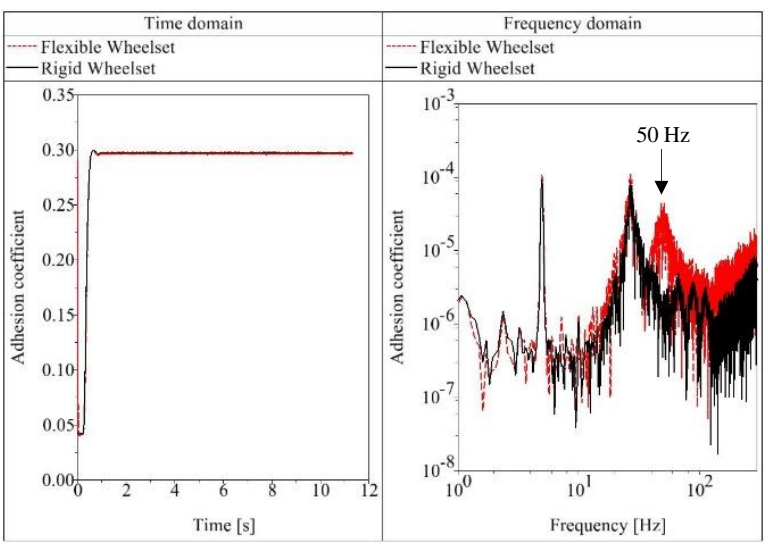

(a) Adhision coefficient

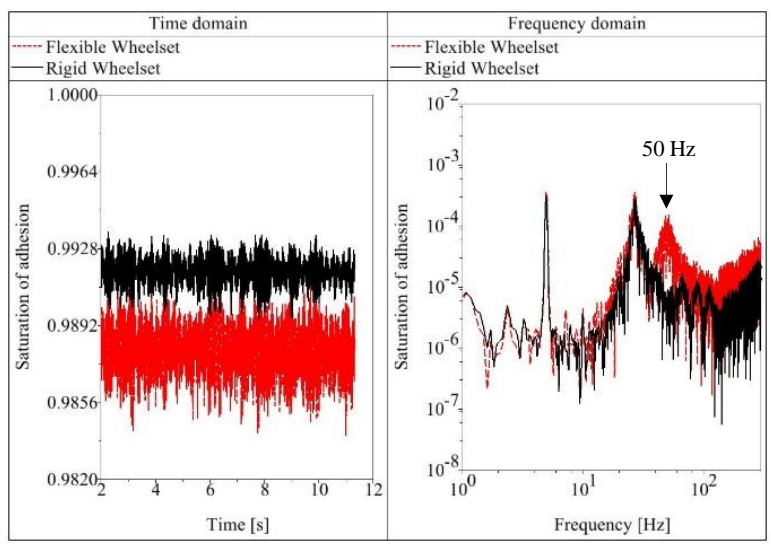

(b) Saturation of adhesion

Figure 9 Adhesion state of the contact on a curve (radius $100 \mathrm{~m}$ )

As can be seen in Figure 9, during the curve negotiation, the adhesion coefficient has reached to 0.3 which is the adhesion limit in this case. The saturation of adhesion is another indicator. The value of 1 means that no further creep forces can be transmitted. It is clear that the contact patch experiences a stick-slip vibration in a nearlysaturated adhesion state. This stick-slip vibration at the contact patch can effectively excite the wheelset torsional mode to fluctuate the contact parameters (especially the creepages) at the wheelset torsional modal frequency, which will finally result in the oscillation of the contact wear at the same frequency.

Apart from the situation of small curve negotiation, high traction torque can also lead to a state of saturated adhesion. It has been found through more simulation that for a power wheelset with high traction torque, if the contact adhesion limit is reached, the wheelset torsional mode will also be excited by the stick-slip vibration. The excited torsional vibration can also fluctuate the contact responses, and thereby initiate a polygonal wear at the wheelset torsional modal frequency. This finding is in accordance with reports by Frohling who found that the wheel polygonization occurring in an electric locomotive in South Africa was caused by the torsional vibration of the wheelset shaft [15]. However the situation of high traction torque is more complicated as it is related to the adhesion control.

\section{Influence of wheelset flexibility on the evolution of wheel polygonization}

\subsection{Prediction of the evolution of wheel polygonization}

A developed method [29] is adopted to predict the evolution of wheel polygonization. It was found that, a continuous excitation with a fixed frequency (track irregularity or sleeper passing frequency, etc) that can fluctuate the contact parameters (normal force, creepages, etc) in the same frequency, will cause a corresponding order of the wheel polygonization to develop, according to Equation (4).

$$
\text { Order }=\frac{\text { Perimeter }}{\text { Wavelength }}=\frac{\text { Frequency }}{\text { Speed }} \times \text { Perimeter }
$$

As an example, assigning a vertical track irregularity with a single sinusoidal wavelength of 1/10 wheel perimeter, the corresponding developed order of the wheel polygonization will be exactly 10. Figure 10 shows the resulting 
development of wheel polygonization for a wheelset running on a straight track. The main simulation parameters for this example are: speed $70 \mathrm{~km} / \mathrm{h}$, wavelength $0.3925 \mathrm{~m}$ (perimeter/10), excitation amplitude $0.1 \mathrm{~mm}$, simulation iterations 10 , amplification coefficient $1 \mathrm{e} 6$, and total running distance $39,250 \mathrm{~km}$.

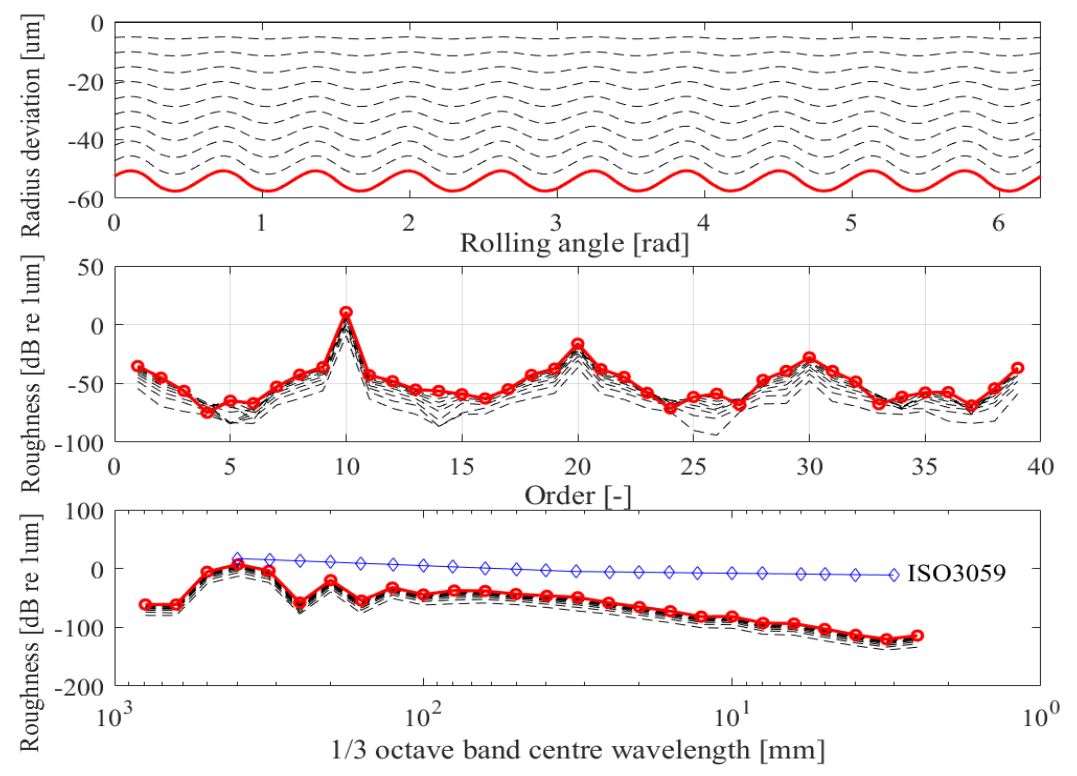

Figure 10 Development of wheel polygonization excited by a vertical track irregularity with a single sinusoidal wavelength of $1 / 10$ wheel perimeter

This is the basic relationship between the excitation frequency and the developed order of the wheel polygonization. It can be extended to the situation of multiple excitation frequencies, which means fluctuation with multiple frequency components occurring in contact parameters can lead to multiple corresponding orders to develop. The prime interest of this paper lies in whether the wheelset flexibility plays an important role in the formation and the growth rate of the wheel polygonization. The idea is that, under the excitation of white noise that has a wide range of frequency components, if some wheelset flexible modes can be successfully excited to fluctuate the contact parameters at the wheelset flexible modal frequencies, and further the circumferential wheel wear at the same modal frequencies, these wheelset flexible modes will result in the development of the corresponding orders of the wheel polygonization. By comparing the evolution of wheel polygonization between rigid and flexible wheelsets, the influence of the wheelset flexibility can be identified.

\subsection{Case studies}

The comparisons were carried out for a straight track and 4 curved tracks with radii of $1200 \mathrm{~m}, 900 \mathrm{~m}, 600 \mathrm{~m}$, and $300 \mathrm{~m}$ respectively. The running speed of $70 \mathrm{~km} / \mathrm{h}$ and the running distance of $39,250 \mathrm{~km}$ are set for all scenarios. But one exception is that, for the curved track of radius $300 \mathrm{~m}$, only $27,475 \mathrm{~km}$ is run, as the wheel-rail contact detachment will occur for further running due to large amount of wheel roughness that developed. Higher frequencies above $300 \mathrm{~Hz}$ of the wheel circumferential wear is filtered as the investigated flexible mode frequencies are below $300 \mathrm{~Hz}$.

White noise with a flat-PSD, which is used as the input for investigating the contact responses, is no longer suitable for checking the development of wheel polygonization. Because given the same amplitude, a sinusoidal excitation with higher frequency has more energy than that with lower frequency, so that the higher orders excited by highfrequency excitations are easier to develop faster than the lower orders excited by low-frequency excitations, if a flat-PSD is used as the excitation. Consequently, the flat-PSD has to be modified so as to obtain a meaningful result when comparing the growth rate of different orders of wheel polygonization. The principle is that the energy should be equally distributed in the frequency domain, which can be guaranteed by Equation (5).

$$
P(f) \times f^{2}=\text { constant }
$$

Where: $f$ is the distance frequency, $P(f)$ is the PSD amplitude at frequency $\mathrm{f}$. Assuming: $P(1) \times 1^{2}=1$, Equation (5) can be written as:

$$
P(f)=1 / f^{2}
$$

Then a random signal in distance domain can be generated by $P(f)$, but should be scaled to adapt for a reasonable track irregularity. In this case, a coefficient of $1 \mathrm{e}-12$ is used. The resulting vertical track irregularity is shown in 
Figure 11. Note that the signal shown has been transformed to the time and frequency domain with speed of 70 $\mathrm{km} / \mathrm{h}$. With this kind of vertical track irregularity as the excitation, the simulation results are shown in Figure 12. By comparing all scenarios in Figure 12, the influence of wheelset flexibility can be interpreted in two aspects: the growth rate and the developed orders.

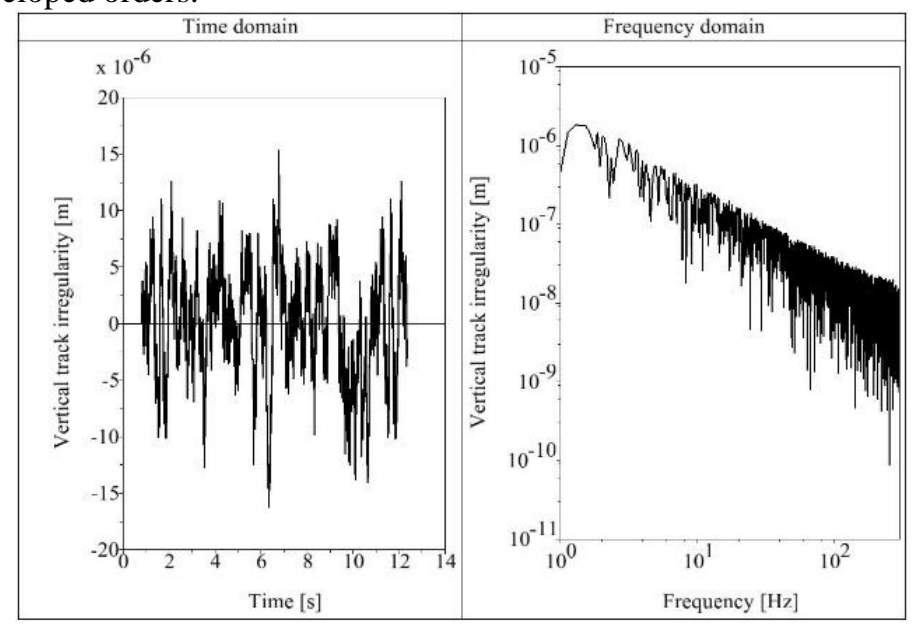

Figure 11 Vertical track irregularity generated by white noise with equally-distributed energy

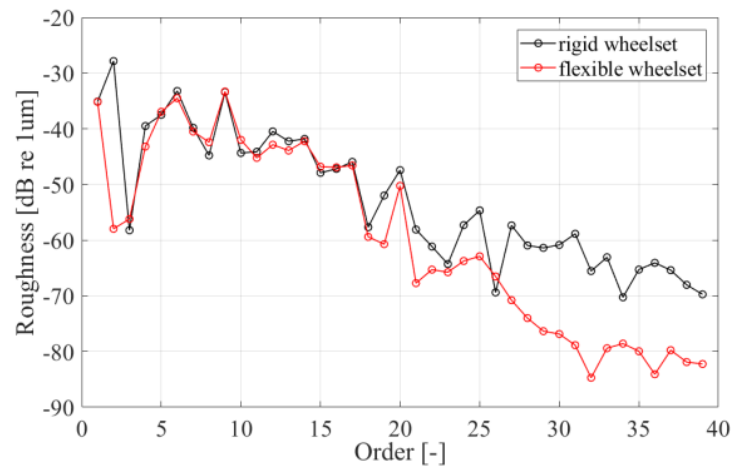

(a) Straight track

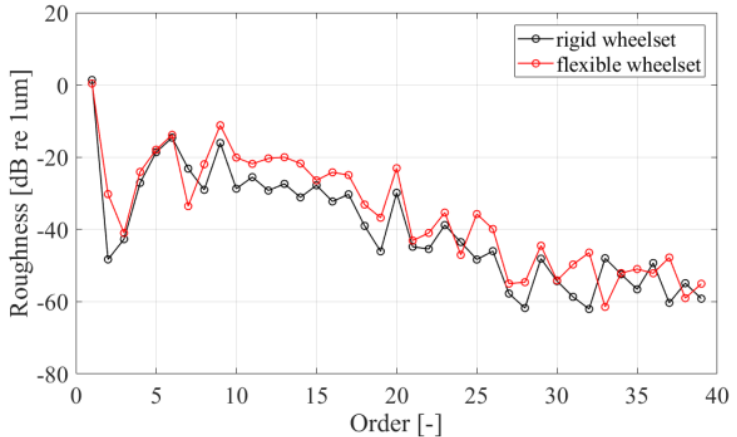

(b) Curved track: radius $1200 \mathrm{~m}$

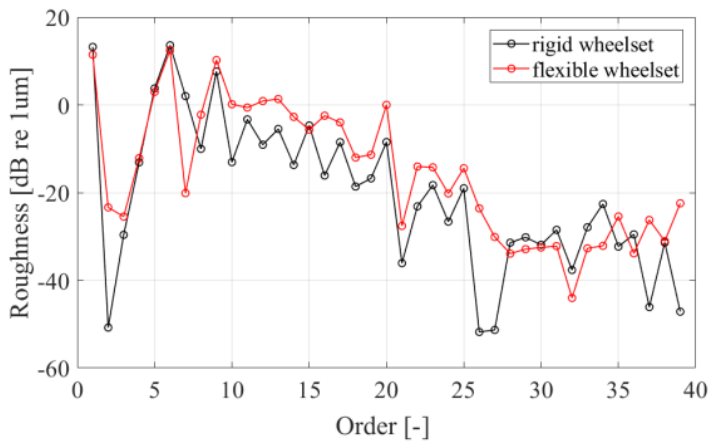

(d) Curved track: radius $600 \mathrm{~m}$

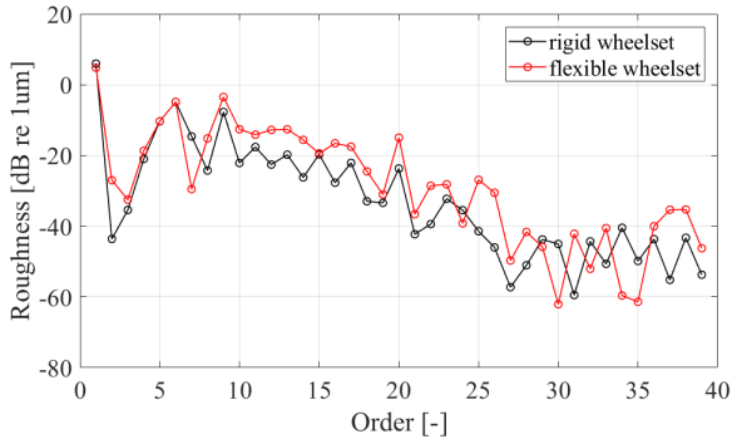

(c) Curved track: radius $900 \mathrm{~m}$

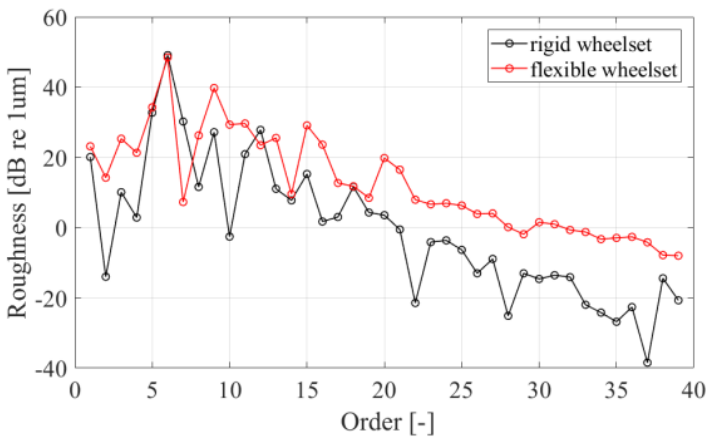

(e) Curved track: radius $300 \mathrm{~m}$ 
Figure 12 Development of wheel polygonization excited by vertical track irregularity (white noise with equallydistributed energy), with running distance of $39,250 \mathrm{~km}$ on (a) straight track, (b) curved track (radius $1200 \mathrm{~m}$ ), (c) curved track (radius $900 \mathrm{~m}$ ), (d) curved track (radius $600 \mathrm{~m}$ ), and with running distance of 27,475 km on (e) curved track (radius $300 \mathrm{~m}$ )

In terms of the growth rate of the wheel polygonization, firstly, there is a general trend that, the smaller the curve radius is, the faster the development of the wheel polygonization will be, and the more obviously that the wheelset flexibility can influence the wear. Secondly, for curved tracks, the wheelset flexibility has an obvious effect on accelerating the growth rate for most orders above the $9^{\text {th }}$. Note that the flexible modal frequency of the wheelset starts from $50.05 \mathrm{~Hz}$ (see Table 2), and the corresponding frequency of the $9^{\text {th }}$ order at the speed of $70 \mathrm{~km} / \mathrm{h}$ is 44.6 $\mathrm{Hz}$, according to Equation 6. It is naturally believed that the flexible modes of the wheelset are attributable to the accelerated growth of orders above $9^{\text {th }}$.

With respect to the developed orders, firstly, there is always a development in the $1^{\text {st }}$ order because of the wheelset imbalance introduced from the FE modelling of the wheelset (see Section 2). This is an artefact of the modelling method, however, it is still reasonable as the wheelsets will always have an imbalance in reality. Secondly, the developed order of 6 appearing in all the scenarios (for Figure 12 (a) to (e)) is due to the vertical rigid body mode of the wheelset \& sleeper with respect to the ground. The frequency of this mode is $27.8 \mathrm{~Hz}$, determined by the mass of wheelset \& sleeper and the vertical stiffness of the sleeper. The corresponding order of $27.8 \mathrm{~Hz}$ at the speed of $70 \mathrm{~km} / \mathrm{h}$ is 5.62 . As 5.62 is closer to integer 6 than integer 5 , the order 6 is developed dominantly followed by the order 5 which is slightly smaller. This dominant order will change with the speed correspondingly, according to Equation (4). In addition, it should be noted that the $6^{\text {th }}$ order is always the most dominant for all scenarios. This is because the vertical rigid mode of wheelset \& sleeper is most readily excited by a vertical excitation as in this case. Of course, the wheelset flexibility is not responsible for the development of the $6^{\text {th }}$ order, as it is due to a rigid mode in this case.

Thirdly, another development in the $9^{\text {th }}$ order apparent in all the scenarios is rather confusing. Because on the one hand, this particular order is also dominant indicating there must be a significant driver, however on the other hand, this order will not change correspondingly with the speed, meaning that it cannot be explained by the fixedfrequency mechanism, as Equation (4) is not satisfied any more. The reason for the development of this order is not clear.

Finally, the major focus of the work presented here is to check whether any flexible modes of the wheelset can be significantly excited to cause some orders to grow. Knowing that the first 3 flexible modal frequencies are 50.05 $\mathrm{Hz}, 71.305 \mathrm{~Hz}$, and $136 \mathrm{~Hz}$, the corresponding orders at speed of $70 \mathrm{~km} / \mathrm{h}$ are $10.1,14.4$, and 27.5 respectively. However, there are not obvious peaks that can be found at the position of these orders, meaning that the wheelset flexibility do not contribute to the wheel polygonalization in these scenarios in Figure 12. However, in the case of a curved track with small radius $(100 \mathrm{~m}$ ) illustrated in Section 4.2, the torsional mode of the wheelset is found to be effectively excited. Based on this finding, a further simulation is carried out to check the effect of the torsional mode on the development of wheel polygonization. The speed is set to $50 \mathrm{~km} / \mathrm{h}$, the running distance is set to only $2,355 \mathrm{~km}$ to avoid contact detachment in simulation due to very large wear. The result is shown in Figure 13 below.

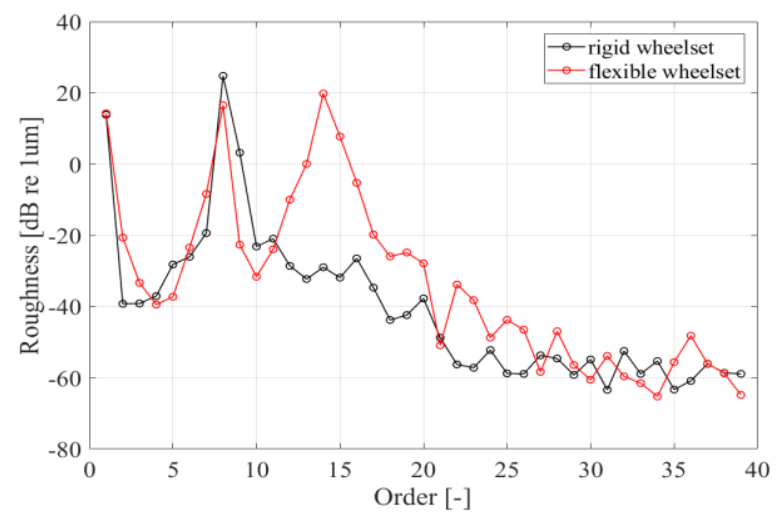

Figure 13 Development of wheel polygonization excited by vertical track irregularity (white noise with equallydistributed energy) with running distance of 2,355 $\mathrm{km}$ on a curved track (radius $100 \mathrm{~m}$ )

The order that is expected to develop due to the torsional mode frequency $50.05 \mathrm{~Hz}$ at speed of $50 \mathrm{~km} / \mathrm{h}$ is $50.05 /(50 / 3.6) /(2 \times \mathrm{pi} \times 0.625) \approx 14$. In Figure 13 , it can be clearly seen that, the $14^{\text {th }}$ order of the wheel 
polygonization is dominantly developed in the presence of wheelset flexibility, compared to the rigid wheelset. More simulation shows that Equation (4) is satisfied when the speed changes. So it is confirmed that the torsional mode of the wheelset is the reason for the formation of the $14^{\text {th }}$ order in this case of an extreme small curve radius. In addition, the development of the $8^{\text {th }}$ order persists because of the vertical rigid mode of wheelset $\&$ sleeper, which has been explained before (noting that the speed is $50 \mathrm{~km} / \mathrm{h}$ for this time).

\section{Conclusions}

This paper reports on fundamental research investigating the influence of wheelset flexibility on polygonal wear of railway wheels. Although the results presented here are from a locomotive wheelset, simulation has also been carried out for the wheelset of a high-speed train $(350 \mathrm{~km} / \mathrm{h})$ using the same method. It turns out that the basic phenomena is similar but with differences being in the maximum frequencies considered and more flexible modes (the $3^{\text {rd }}$ and $4^{\text {th }}$ bending mode, in-phase umbrella mode, etc) involved. In addition, another finding of less importance is that, the $2^{\text {nd }}$ wheelset flexible mode can be excited by lateral rail irregularity (which can drive fluctuating lateral creepage) but the excited mode has limited influence on the polygonal wear. Based all the results obtained, some general conclusions can be drawn as follows:

1. The influence of wheelset flexibility on the development of railway wheel polygonization is complicated because the results strongly depend on specific conditions. All the investigated wheelset flexible modes (the torsional mode, the $1^{\text {st }}$ bending mode, the $2^{\text {nd }}$ bending mode and the umbrella mode) are found to influence the contact responses, but in very different ways and having different effects on the wheel wear. By further considering that in reality the attachment constrains (gear box, motor suspension tube, or brake equipment) would more or less prevent the wheelset flexibility from being excited, it is believed that the wheelset flexibility cannot dominate the railway wheel polygonization in a general sense. In other words, some prerequisites must be fulfilled to provide a suitable environment for the wheelset flexibility to be effectively and continually excited to fluctuate the contact responses, and thereby initiate wheel polygonization.

2. The wheelset flexibility tends to attenuate the normal force slightly, but can always increase the lateral creepage significantly. The normal force is not easy to be influenced by any wheelset flexible modes in the frequency domain. The lateral creepage is sensitive to the $1^{\text {st }}$ bending mode and the umbrella mode under excitation of vertical track irregularity, and sensitive to the $2^{\text {nd }}$ bending mode under excitation of lateral track irregularity. The longitudinal creepage is mainly sensitive to the torsional mode, although can also be affected by other flexible modes but not so apparently.

3. When the contact adhesion is nearly saturated, which can happen on track with small curve radii or due to large traction torque, the stick-slip vibration occurring at the contact patch can effectively excite the wheelset torsional mode to fluctuate the contact parameters and therefore the wheel wear. If this situation persists for a long time, the development of the wheel polygonization can be expected. The excited order will be exactly determined by the wheelset torsional modal frequency and the vehicle speed.

The future work is to address some unexplained issues in this paper. More investigation is being undertaken by adopting a full vehicle with real wheel polygonization and comparing with other important factors, e.g. the track flexibility.

\section{Funding}

The present work is supported by CRRC Zhuzhou Locomotive Co.,Ltd, and Institute of Railway Research, University of Huddersfield. The support of these organization is gratefully acknowledged.

\section{References}

[1] X. Jin, L. Wu, J. Fang, S. Zhong, L. Ling, An investigation into the mechanism of the polygonal wear of metro train wheels and its effect on the dynamic behaviour of a wheel/rail system, Vehicle System Dynamics, 50 (2012) 1817-1834.

[2] A. Johansson, J.C.O. Nielsen, Out-of-round railway wheels - Wheel-rail contact forces and track response derived from field tests and numerical simulations, Proceedings of the Institution of Mechanical Engineers, Part F: Journal of Rail and Rapid Transit, 217 (2003) 135-145. 
[3] B. Morys, Enlargement of out-of-round wheel profiles on high speed trains, Journal of Sound and Vibration, 227 (1999) 965-978.

[4] J. Kalousek, K.L. Johnson, An Investigation of Short Pitch Wheel and Rail Corrugations on the Vancouver Mass Transit System, Proceedings of the Institution of Mechanical Engineers, Part F: Journal of Rail and Rapid Transit, 206 (1992) 127-135.

[5] H.P. Kaper, Wheel corrugation on Netherlands railways (NS): Origin and effects of "polygonization" in particular, Journal of Sound and Vibration, 120 (1988) 267-274.

[6] G. Tao, L. Wang, Z. Wen, Q. Guan, X. Jin, Measurement and assessment of out-of-round electric locomotive wheels, Proceedings of the Institution of Mechanical Engineers, Part F: Journal of Rail and Rapid Transit, (2016). [7] Y. Wu, X. Du, H.-j. Zhang, Z.-f. Wen, X.-s. Jin, Experimental analysis of the mechanism of high-order polygonal wear of wheels of a high-speed train, Journal of Zhejiang University-SCIENCE A, 18 (2017) 579-592. [8] W. LI, Y. LI, X. ZHANG, Mechanism of the polygonal wear of metro train wheels, Journal of Mechanical Engineering, 49 (2013) 17-22.

[9] G. Tao, L. Wang, Z. Wen, Q. Guan, X. Jin, Experimental investigation into the mechanism of the polygonal wear of electric locomotive wheels, Vehicle System Dynamics, (2017) 1-17.

[10] L. Wei, L. Zong, S. Luo, X. He, Research into the problem of wear creating a polygon-shaped wheel on metro trains, Proceedings of the Institution of Mechanical Engineers, Part F: Journal of Rail and Rapid Transit, 230 (2016) 43-55.

[11] M. Meywerk, Polygonalization of railway wheels, Archive of Applied Mechanics, 69 (1999) 105-120.

[12] A. Johansson, C. Andersson, Out-of-round railway wheels-a study of wheel polygonalization through simulation of three-dimensional wheel-rail interaction and wear, Vehicle System Dynamics, 43 (2005) 539-559.

[13] P. Meinke, S. Meinke, Polygonalization of wheel treads caused by static and dynamic imbalances, Journal of Sound and Vibration, 227 (1999) 979-986.

[14] C. Guangxiong, C. Xiaolu, W. Ke, Generation Mechanism for Plolygonalization of Wheel Treads of HighSpeed Trains, Journal of Southwest jiaotong University, 51 (2016) 244-250.

[15] U.S. Robert Fröhling, Eduard Reitmann, Locomotive wheel tread polygonisation caused by torsional axle shaft vibration, 11th international conference on contact mechanics and wear of rail/wheel systems (CM2018), Delft, the Netherlands, 2018, pp. 261-270.

[16] K. Popp, I. Kaiser, H. Kruse, System dynamics of railway vehicles and track, Archive of Applied Mechanics, 72 (2003) 949-961.

[17] K. Popp, H. Kruse, I. Kaiser, Vehicle-Track Dynamics in the Mid-Frequency Range, Vehicle System Dynamics, 31 (1999) 423-464.

[18] M. Fermer, J.C.O. Nielsen, Wheel/Rail Contact Forces for Flexible versus Solid Wheels due to Tread Irregularities, Vehicle System Dynamics, 23 (1994) 142-157.

[19] N. Chaar, M. Berg, t. Skolan för, Järnvägsteknik, f. Farkost och, Kth, Vehicle-Track Dynamic Simulations of a Locomotive Considering Wheelset Structural Flexibility and Comparison with Measurements, Proceedings of the Institution of Mechanical Engineers, Part F: Journal of Rail and Rapid Transit, 219 (2005) 225-238.

[20] A. Guiral, A. Alonso, J.G. Giménez, Vehicle-track interaction at high frequencies - Modelling of a flexible rotating wheelset in non-inertial reference frames, Journal of Sound and Vibration, 355 (2015) 284-304.

[21] L. Baeza, J. Fayos, A. Roda, R. Insa, High frequency railway vehicle-track dynamics through flexible rotating wheelsets, Vehicle System Dynamics, 46 (2008) 647-659.

[22] P.T. Torstensson, J.C.O. Nielsen, L. Baeza, T. Chalmers University of, D. Institutionen för tillämpad mekanik, E. School of Mechanical, D. Department of Applied Mechanics, h. Chalmers tekniska, Dynamic train-track interaction at high vehicle speeds-Modelling of wheelset dynamics and wheel rotation, Journal of Sound and Vibration, 330 (2011) 5309-5321.

[23] TB/T449-2016, Wheel profile for locomotive and car, Chinese state railway administration, 2016.

[24] GB2585-2007, Hot-rolled steel rails for railway, Chinese standardization administration, 2007.

[25] R. Craig, R, M. Bampton, C C, Coupling of Substructures for Dynamic Analyses, AIAA Journal, 6 (1968) 1313-1319.

[26] W. Zhai, Vehicle-Track Coupling Dynamics, Science Press, Beijing China, 2007.

[27] S. Iwnicki, Simulation of wheel-rail contact forces, Fatigue \& Fracture of Engineering Materials \& Structures, 26 (2003) 887-900.

[28] T. Jendel, M. Berg, Prediction of Wheel Profile Wear, Vehicle System Dynamics, 37 (2002) 502-513.

[29] B. Peng, S. Iwnicki, P. Shackleton, Y. Zhao, D. Cui, A practical method for simulating the evolution of railway wheel polygonalization, 25th international symposium on dynamics of vehicles on roads and tracks, Rockhampton, Australia, 2017, pp. 753-758. 